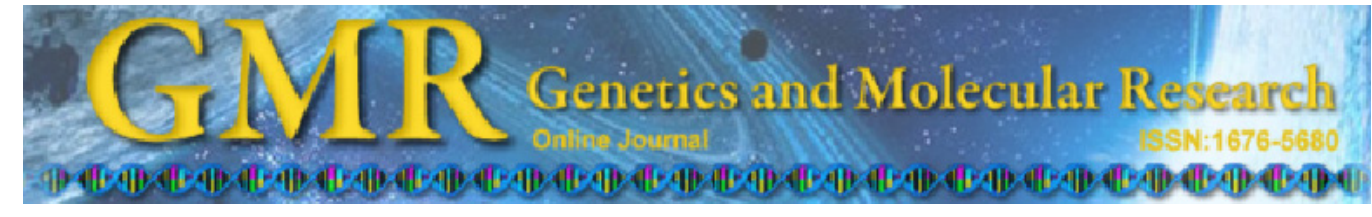

\title{
Neural-endocrine mechanisms of respiratory syncytial virus-associated asthma in a rat model
}

\author{
Q.G. $\mathrm{Li}^{1 *}$, X.R. $\mathrm{Wu}^{2 *}$, X.Z. $\mathrm{Li}^{3}$, J. Yu${ }^{1}$, Y. Xia ${ }^{1}$, A.P. Wang ${ }^{1}$ and J. Wang ${ }^{1}$ \\ ${ }^{1}$ Second Department of Respiratory Disease, \\ Jiangxi Provincial People's Hospital, Nanchang, P.R. China \\ ${ }^{2}$ Department of Ophthalmology, First Affiliated Hospital, \\ Nanchang University, Nanchang, P.R. China \\ ${ }^{3}$ Department of Nephrology, Central South University, Xiangya Hospital, \\ Changsha, P.R. China \\ *These authors contributed equally to this study. \\ Corresponding author: J. Wang \\ E-mail: wangjun5087@163.com
}

Genet. Mol. Res. 11 (3): 2780-2789 (2012)

Received October 4, 2011

Accepted July 10, 2012

Published August 24, 2012

DOI http://dx.doi.org/10.4238/2012.August.24.3

\begin{abstract}
We examined the underlying neural-endocrine mechanisms of asthma associated with respiratory syncytial virus infection. Thirty Sprague-Dawley rats were randomly divided into control group, respiratory syncytial virus (RSV) group, and anti-nerve growth factor (NGF) IgG group. An RSV infection model was established by nasal drip once a week. In the anti-NGF antibody intervention group, each rat was given an intraperitoneal injection of anti-NGF IgG $3 \mathrm{~h}$ before RSV infection. Optical microscopy and transmission electron microscopy were used to observe the structural changes in adrenal medulla cells. Changes in adrenaline and norepinephrine in serum were detected by ELISA. NGF expression was assayed by immunohistochemistry. Expression differences in synaptophysin mRNA were detected by RT-PCR. Transmission electron microscopy displayed widened adrenal medulla intercellular spaces, reduced chromaffin particle concentration, and increased mitochondria in the RSV infection group. At the same time, NGF expression was increased in the RSV infection group significantly. In addition, the adrenaline concentration was significantly
\end{abstract}


decreased compared with the control and anti-NGF antibody groups. Synaptophysin mRNA expression was significantly increased in the RSV infection and anti-NGF antibody groups. However, compared with the RSV infection group, synaptophysin mRNA expression was significantly decreased in the anti-NGF antibody group. We conclude that RSV infection could induce adrenal medulla cell differentiation to nerve cells by over-expression of NGF, resulting in the decreased endocrine function found in asthma progression.

Key words: Respiratory syncytial virus; Adrenal medulla cell; Nerve growth factor; Synaptophysin

\section{INTRODUCTION}

Respiratory syncytial virus (RSV) is the most common cause of lower respiratory tract infections in young infants, and virtually all children experience RSV infection at least once during the first 2 years of life (Welliver, 2003; Psarras et al., 2004). A wide range of epidemiological studies support the observation that infants with recurrent RSV infection are more prone than others to develop asthmatic bronchitis and bronchial asthma some years later (Mohapatra and Boyapalle, 2008; Stensballe et al., 2009).

Recent studies have demonstrated that nerve growth factor (NGF)-mediated neurogenic inflammation plays an important role in RSV infection. Studies have shown a significant increase in the levels of NGF and its receptor in lung tissue (Hu et al., 2002) and bronchoalveolar lavage fluid (Tortorolo et al., 2005). Furthermore, NGF overexpression may induce airway hyper-responsiveness (AR) and asthma via a neuroimmune mechanism (Braun et al., 1999; Shen et al., 2006). Although this mechanism can explain the symptoms of acute response to RSV infection, the intrinsic relationship between RSV infection and high incidence of asthma is still unclear.

Imbalance of the excitability or suppression of adrenergic and/or cholinergic nerves and corresponding receptor systems, which dominate the airway, is well-known to be the immediate cause of wheezing and asthma attacks; the regulation of airway patency has been achieved mainly through the synthesis and secretion of epinephrine by adrenal medulla cells to antagonize the pathological and physiological mechanisms involved in asthma, such as bronchoconstriction (Feng and $\mathrm{Hu}, 2005$ ). However, when adrenomedullary chromaffin cells are affected by any lesion, the synthesis and release of epinephrine would be reduced (Greene and Tischler, 1976). Our previous studies have also confirmed that the epinephrine concentration in blood circulation decreased markedly in the bronchial asthma state. Therefore, we speculated that the abnormal functioning of adrenal medullary cells might be involved in the pathogenesis of RSV-induced asthma and that NGF overexpression may be a crucial link in the neuroendocrine mechanism of RSV infection (Wang et al., 2006).

\section{MATERIAL AND METHODS}

\section{Material}

Thirty healthy Sprague-Dawley rats (aged 1 week and weighing 12-15 g) were pro- 
vided by the Animal Center of Jiangxi College of Traditional Chinese Medicine. The animals were maintained under a strict specific-pathogen-free condition. Specimens of the A2 strain of RSV and HeLa cervical carcinoma cells were obtained from the Department of Microbiology and Pharmacology, Xiangya Medical College.

\section{Methods}

\section{RSV viral suspension preparation and toxicity detection}

RSV suspensions were prepared using a previously described method (Wedde-Beer et al., 2002; Auais et al., 2003). Confluent monolayers of HeLa cells were infected with RSV strain $\mathrm{A} 2$, and the infection was allowed to progress at $37^{\circ} \mathrm{C}$ in $5 \% \mathrm{CO}_{2}$ atmosphere until $100 \%$ of the cells exhibited a cytopathic effect (for 2-5 days). Cell debris was removed by centrifugation at $800 \mathrm{~g}$ for $10 \mathrm{~min}$ in a centrifuge refrigerated at $4^{\circ} \mathrm{C}$. Before inoculation, the virus stock was titrated and diluted as needed to obtain a final titer of $5 \times 10^{4} 50 \%$ tissue culture infective dose $\left(\mathrm{TCID}_{50}\right)$ in $0.1 \mathrm{~mL}$. Supernatants and cell lysates from virus-free HeLa flasks were harvested, centrifuged, and separated into aliquots according to the same protocol used to obtain virus-free medium for use as the negative control.

\section{Animal treatment}

The 30 healthy Sprague-Dawley rats were randomly divided into 3 groups (Hu et al., 2002): 1) RSV infection group, 2) anti-NGF antibody group, and 3) control group. The rats in the RSV infection group were inoculated with RSV suspension $(0.4 \mu \mathrm{L} / \mathrm{g})$ by nasal drip and then raised separately. This treatment process was repeated once a week. In the anti-NGF antibody group, each rat was administered an intraperitoneal injection of anti-NGF IgG (dilution 1:1000, $4 \mathrm{~mL} / \mathrm{kg}) 3 \mathrm{~h}$ before being infected with SRV. The control rats were administered an intraperitoneal injection of purified IgG (dilution 1:1000, $4 \mathrm{~mL} / \mathrm{kg}$ ), followed by injection of virus-free medium. After 12 weeks, AR was measured in each group and executed to collect tissue samples.

\section{AR measurement}

AR was measured in animals by whole-body plethysmography (Buxco, France), as described previously (Dong et al., 2005; Witzenrath et al., 2006). Briefly, rats were anesthetized by intraperitoneal injection of $20 \%$ pentobarbital sodium $(30 \mathrm{mg} / \mathrm{kg})$ and then placed in a supine position to perform tracheostomy. Inhalation airway provocation was performed with aerosolized phosphate-buffered saline (PBS; baseline) and increasing doses of histamine hydrochloride $(0.01-0.16 \mathrm{mg} / \mathrm{mL})$ for $20 \mathrm{~s}$ each. Airway resistance values for different histamine hydrochloride concentrations were normalized to the PBS baseline value (1.00).

\section{In situ hybridization (ISH) of RSV in lung tissue}

The sequences of RSV mRNA probe (Haoyang, Tianjin) were 5'-GGTTGACTTGAC TCCTGGTGTTGTTGA-3' and 5'-TAGCGATTTGATTTGTTACTTATTCCTGC-3'. Paraffinembedded specimens were deparaffinized and rehydrated by traditional methods. The tissue 
sections were blocked by immersion in $\mathrm{H}_{2} \mathrm{O}_{2}$ at room temperature for 20 min. They were further digested with a working solution at room temperature for $10 \mathrm{~min}$ and then incubated in prehybridization solution at $37^{\circ} \mathrm{C}$ for $1 \mathrm{~h}$ in a humidified chamber. Slides were washed thrice in $0.2 \mathrm{X}$ saline sodium citrate (SSC). For hybridization, each slide was incubated in a hybridization solution at $37^{\circ} \mathrm{C}$ for $4 \mathrm{~h}$ in a humidified chamber, and then, the sections were washed thrice in $2 \mathrm{X} \mathrm{SSC}$ and $0.2 \mathrm{X} \mathrm{SSC}$. Each slide was carried out by a diluted solution containing the anti-DIG antibody, and then subjected to the solution containing the highly sensitive peroxidase-chain-avidin at $37^{\circ} \mathrm{C}$ for $45 \mathrm{~min}$ in a humidified chamber. Finally, they were stained with diaminobenzidine and counterstained with hematoxylin. Brown color could be observed in the cytoplasm under optical microscopy when the sample tested positive.

\section{Microscopic observation of adrenal medulla cells}

The pathological changes of adrenal medulla cells were first examined by hematoxylin-eosin staining under an optical microscopy. Furthermore, the ultra-structure was observed by transmission electron microscopy (TEM). Adrenal gland tissue was fixed in $2.5 \%$ glutaraldehyde. After washing with $0.01 \mathrm{M}$ PBS, the samples were post-fixed in $1 \%$ osmium tetraoxide. They were dehydrated in a graded acetone series and embedded in epoxy resin EPON812. The ultra-thin sections on grids were stained with aqueous uranyl acetate followed by a leadelectron staining solution. The sections were observed using an H600 electron microscopy, and images were observed.

\section{Immunohistochemistry analysis of NGF expression}

NGF expression was determined by the standard streptavidin-biotin-peroxidase complex method. NGF antibody was used at a concentration of 1:250. Goat serum, biotinylated secondary antibody (goat anti-mouse $\operatorname{IgG}$ ), and diaminobenzidine were all purchased from Boster. For negative controls, the slides were treated with PBS in place of the primary antibody.

\section{Semi-quantitative RT-PCR quantification of synaptophysin (SYN) mRNA}

Total RNA was isolated from adrenal medulla cells using the Trizol kit according to manufacturer instructions. cDNA was synthesized using $2 \mu \mathrm{g}$ RNA with oligo(dT) primers and $\mathrm{M}_{2}$ MLV reverse transcriptase (Sangon, Shanghai). The $25-\mu \mathrm{L}$ PCR mixture contained $2 \mu \mathrm{L}$ cDNA, sense and anti-sense primers (each $2 \mu \mathrm{L}$ ), $2.5 \mu \mathrm{L} \mathrm{MgCl}_{2}, 1 \mu \mathrm{L}$ dNTPs, $0.5 \mu \mathrm{L}$ TagDNA, and $15 \mu \mathrm{L}$ Rnase-free $\mathrm{H}_{2} \mathrm{O}$. The PCR conditions were as follows: initial denaturation at $94^{\circ} \mathrm{C}$ for $5 \mathrm{~min}$; 35 cycles of amplification $\left(94^{\circ} \mathrm{C}\right.$ for $60 \mathrm{~s}, 58^{\circ} \mathrm{C}$ for $60 \mathrm{~s}$, and $72^{\circ} \mathrm{C}$ for $60 \mathrm{~s}$ ), and finally $72^{\circ} \mathrm{C}$ for $5 \mathrm{~min}$. The PCR primers used were as follows: SYN, the forward primer $5^{\prime}-\mathrm{TGT}$ ACTTTGATGCACCCTCC2TGCG-3', and the backward primer 5'-CAGCCTGTCTCCTTG AACACG2AACC-3'. $\beta$-actin was used as an internal control to adjust the SYN amplification. The sense primer used was 5'-GGGAAATCGTGCGTGACA-3' and the anti-sense primer was 5'-GGAAGGAAGGCTGGAAGAG-3'; the amplification products were 448 and $183 \mathrm{bp}$, respectively. PCR products were separated by electrophoresis on $1 \%$ agarose gels and quantified by Eagle Eye II Video Imaging System (Stratagene, CA, USA). SYN mRNA level was normalized to $\beta$-actin expression (relative expression). 


\section{Statistical analysis}

Image gray values (A) and other data were analyzed by using SPSS11.5, and the results were measured by average \pm standard deviation (means $\pm \mathrm{SD}$ ). One-way ANOVA was used to compare different treatment groups. Intragroup comparison was performed using the $t$-test. $\mathrm{P}<0.05$ was considered to be statistically significant.

\section{RESULTS}

\section{Measurement of airway responsiveness}

The PBS baseline values in the RSV infection group and anti-NFG group did not differ. However, in the RSV infection group, the airway resistance value increased significantly with an increase in the histamine hydrochloride concentration; a 2-fold increase in airway resistance value was noted for a histamine hydrochloride concentration of $0.08 \mathrm{mg} / \mathrm{mL}$. The airway resistance values of the RSV infection group and anti-NFG antibody group were significantly different from that of the control group $(\mathrm{P}<0.05)$.

\section{RSV viral ISH in lung tissue}

The RSV mRNA signal could only be seen in the tissue sections of the RSV infection group (Figure 1). Prominent cytoplasmic staining for RSV mRNA was detected in the bronchia and alveolar epithelial cells. No staining was detected in the control sections. These results confirmed the successful establishment of the RSV infection model.

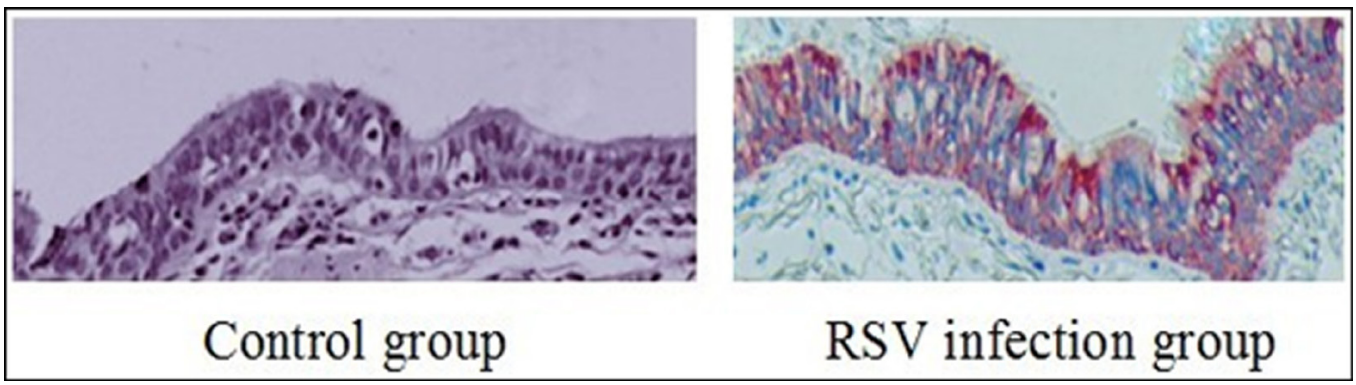

Figure 1. In situ hybridization result of airway tissue (100X). Compared to control, the respiratory syncytial virus (RSV) mRNA signal is seen in bronchia and alveolar epithelial cells in the infection group.

\section{Microscopic observation of adrenal medulla cells}

Observation under an optical microscopy (Figure 2) revealed that in the control group, the cells of the adrenal cortex and medulla were regular in arrangement. However, in the RSV infection group, all the sections showed vacuolated degeneration of adrenal medulla cells and increased lipid levels; a few sections even showed obvious appearance of fiber in the cortex. Further, in the control group, TEM observation (Figure 3) revealed that medullary cells 
featured a larger soma, smooth cell membrane, clear mitochondria, endoplasmic reticulum, and nuclear membrane, with an even distribution of chromaffin particles in the cytoplasm and round nucleus. In the RSV infection group, the medullary cells were characterized by abundant mitochondria, increased lipid levels, reduced chromaffin granules, and obvious clublike protrusions (as shown with red arrows) in the cell membrane. In addition, some of the medullary cells showed nuclear membrane shrinkage and vesicle formation that abut the cell membrane. The anti-NGF antibody group showed intact medulla cell membrane and nucleus, abundant mitochondria, and reduced chromaffin granules. No obvious club-like protrusions and vesicles were noted in the cell membrane.

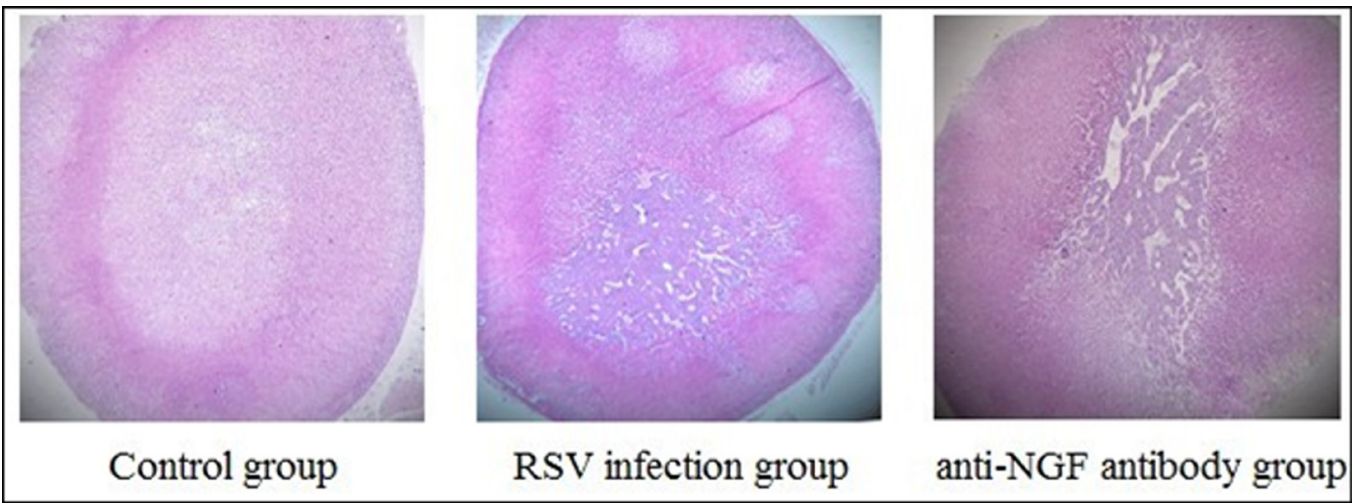

Figure 2. Optical microscopy analysis of adrenal tissue (100X). Adrenal medulla cells of the respiratory syncytial virus (RSV) infection group show vacuolated degeneration, increasing lipid. NGF = nerve growth factor.

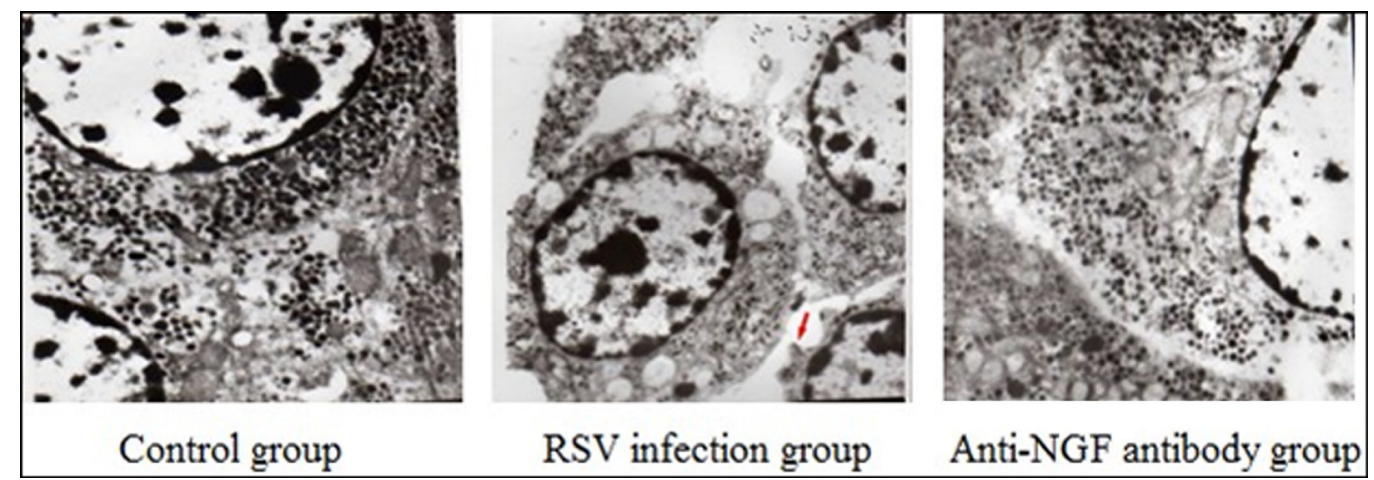

Figure 3. Transmission electron microscopy analysis of adrenal medulla tissue $(10,000 \mathrm{X})$. After respiratory syncytial virus (RSV) infection, medulla cells show significant pathological changes, mitochondrial abundance, lipid increased, and obviously club-like protrusions (red arrows) in cell membrane. NGF $=$ nerve growth factor.

\section{IHC analysis of NGF expression}

NFG expression, which was indicated by brown cytoplasmic staining, was observed in all groups (Figure 4). NGF expression was significantly higher in the RSV infection 
group $(\mathrm{A}=112 \pm 21)$ than in the control $(\mathrm{A}=148 \pm 16)$ and anti-NGF antibody groups $(\mathrm{A}=$ $130 \pm 25)$, and the difference between the anti-NGF antibody group and control group was significant.

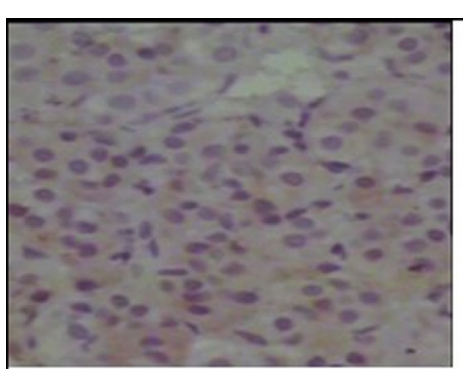

Control group

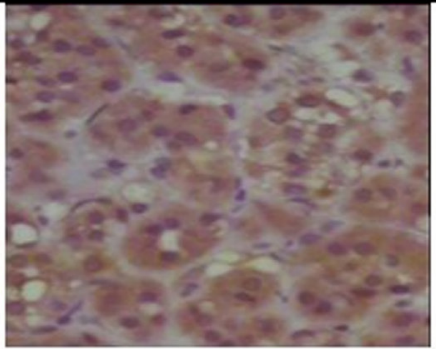

RSV infection group

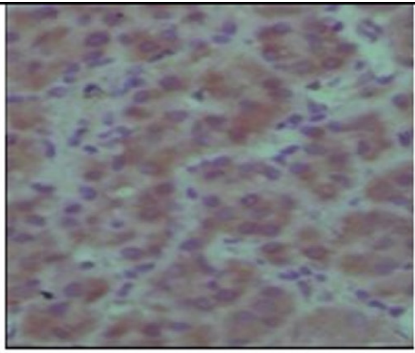

Anti-NGF antibody group

Figure 4. Immunohistochemistry analysis of nerve growth factor (NGF) expression (200X). NGF expression is significantly increased in the respiratory syncytial virus (RSV) infection group compared with control and antiNGF antibody groups.

\section{The changes of adrenaline and norepinephrine concentration}

The adrenaline and norepinephrine concentrations were analyzed by the ELISA method. Table 1 shows that the adrenaline concentration in the control group was significantly different from those in the RSV infection and anti-NGF antibody groups $(\mathrm{P}<0.01)$. A significant difference was noted between the anti-NGF antibody and RSV infection groups ( $\mathrm{P}$ $<0.01)$. However, no intergroup differences were noted in the norepinephrine concentration $(\mathrm{P}>0.05)$.

Table 1. Comparison of adrenaline and norepinephrine in each group (means $\pm \mathrm{SD})$.

\begin{tabular}{lcc}
\hline Group $(\mathrm{N}=10)$ & Adrenaline $(\mathrm{ng} / \mathrm{mL})$ & Norepinephrine $(\mathrm{ng} / \mathrm{mL})$ \\
\hline Control & $6.2 \pm 0.5$ & $53 \pm 4$ \\
RSV infection & $4.3 \pm 0.3^{*}$ & $48 \pm 7$ \\
Anti-NGF antibody & $5.1 \pm 0.6^{* \Delta}$ & $56 \pm 9$ \\
P & 0.00 & $>0.05$ \\
\hline
\end{tabular}

NGF $=$ nerve growth factor. $* \mathrm{P}<0.01$ compared with the control group. ${ }^{\wedge} \mathrm{P}<0.01$ compared with the respiratory syncytial virus (RSV) group.

\section{Semi-quantitative RT-PCR quantification of SYN mRNA}

SYN mRNA expression was detected by RT-PCR (Figure 5). Table 2 shows that the levels of SYN mRNA expression were significantly higher in the RSV infection and anti-NGF antibody groups than in the control group $(\mathrm{P}<0.05)$. However, compared to the RSV infection group, the anti-NGF antibody group showed significantly lower levels of the SYN mRNA expression $(\mathrm{P}<0.05)$. 


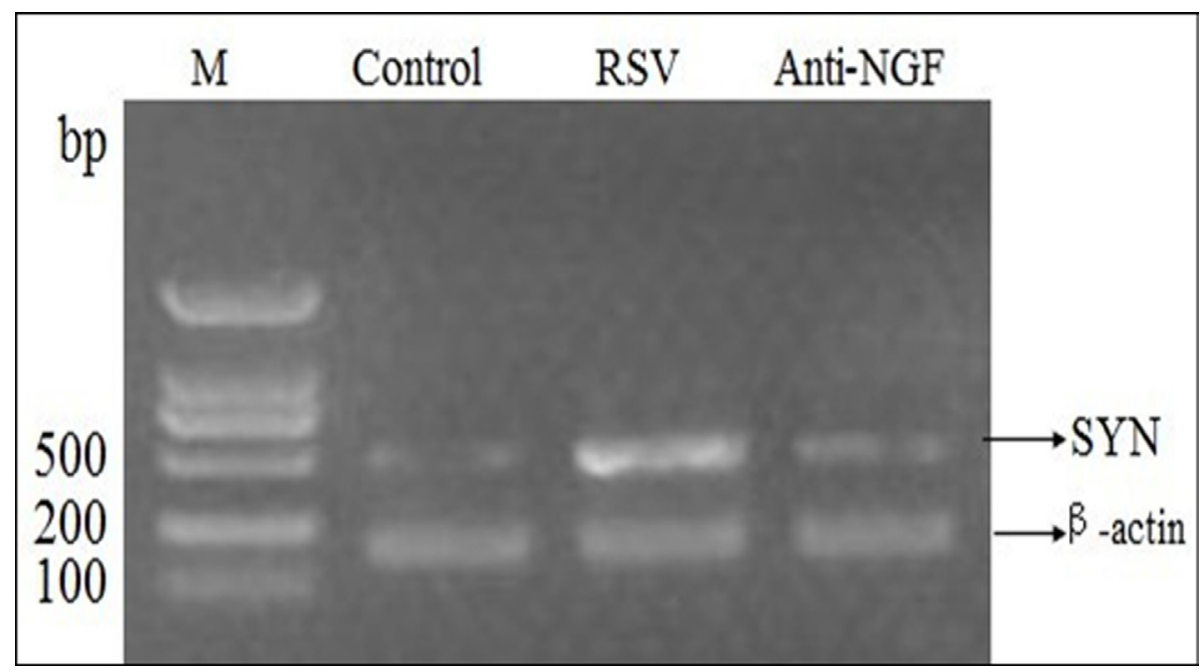

Figure 5. RT-PCR analysis of synaptophysin (SYN) expression. The SYN mRNA expression was significantly increased in the respiratory syncytial virus (RSV) infection group compared to the control group. However, the SYN mRNA expression was moderately increased in the anti-nerve growth factor (NGF) antibody group.

Table 2. Synaptophysin (SYN) mRNA expression in each group (means \pm SD).

\begin{tabular}{lcc}
\hline Group $(\mathrm{N}=10)$ & SYN mRNA & SYN/ $\beta$-actin mRNA \\
\hline Control & $121.13 \pm 5.11$ & $0.25 \pm 0.09$ \\
RSV infection & $78.53 \pm 3.21^{*}$ & $0.53 \pm 0.13^{*}$ \\
Anti-NGF antibody & $101.52 \pm 4.35^{* \mathbf{\Delta}}$ & $0.38 \pm 0.11^{* \boldsymbol{\Delta}}$ \\
\hline
\end{tabular}

NGF $=$ nerve growth factor. ${ }^{*} \mathrm{P}<0.05$ compared with the control group. ${ }^{\mathbf{}} \mathrm{P}<0.05$ compared with the respiratory syncytial virus (RSV) group.

\section{DISCUSSION}

NGF, the best characterized member of the neurotrophin, is not only required for survival but also plays an important role in several signaling events, such as neuron survival, proliferation, differentiation, neuritis outgrowth, and neurotransmitters, under normal physiological condition (Wiesmann et al., 1999; Huang and Reichardt, 2001; Freund-Michel and Frossard, 2008). However, in a pathological state, NGF is over-produced and secreted by target cells to reach the neuronal cell bodies by retrograde axonal distal transport from peripheral neurons, which led to changes in neuronal plasticity (Ye et al., 2003). Some studies have shown that NGF was expressed at high levels in structural and inflammatory cells of the lungs in an asthmatic state (Bonini et al., 2002; Hahn et al., 2006). Our previous studies have indicated that NGF was also highly expressed in adrenal medullary cells (Jun et al., 2007; Feng et al., 2010). In this study, we further found that NGF expression in adrenal medullary cells increased significantly after RSV infection, but anti-NGF antibody could decrease NGF expression to some extent. Put together, our results suggested that adrenal medullary cells are a source of NGF. 
The adrenal medulla is derived from the sympathoadrenal progenitor cell lineage of the epiblast neural crest (Unsicker et al., 2005). Under physiological conditions, the sympathoadrenal progenitor can differentiate into 2 types of cells: 1) sympathetoblasts, which form sympathetic ganglionic cells on maturity, and 2) pheochromoblasts, which form chromaffin cells on maturity. A previous study (Unsicker et al., 1978) proved that adrenomedullary chromaffin cells exhibit the endocrine phenotype, which can secrete a certain concentration of adrenaline to maintain airway patency. Moreover, because they have the same origin as nerve cells, they also have potential nerve cell functions and can differentiate into sympathetic neurons. This hypothesis has also been verified in both in vivo and in vitro models (Aloe and LeviMontalcini, 1979; Lillien and Claude, 1985). Sympathetic neurons can secrete norepinephrine and dopamine, but not adrenaline. This is in agreement with the findings of our previous study that the exogenous-NGF-induced differentiation of primary culture of neonatal calf medulla cells into sympathetic neurons was accompanied by a decline in their secretory function, as indicated by the structural and functional changes in the cells (Wang et al., 2006). In this study, TEM observation of the specimens from the RSV infection group revealed widening of the intercellular spaces of the adrenal medulla, reduction in the concentration of chromaffin particles, increase in the mitochondria, club-like and villous protrusions in the cell membrane, and vesicle formation near the cell membrane surface. Further, the serum adrenaline concentration in the RSV infection group was significantly lesser than those in the control and anti-NGF antibody groups; this implied that the overexpression of NGF in RSV infection might induce the differentiation of the adrenal medullary cells of the endocrine phenotype, as mentioned above, and downregulate adrenaline expression, thereby promoting the progression of asthma.

SYN, a marker protein for synaptic vesicle and an important component of the axon skeleton, is widely distributed in neuroendocrine tissue, including neural tissue, such as the brain, spinal cord, retina, and adrenal medulla (Shojo and Kibayashi, 2006; Kasprzak et al., 2007). Changes in its expression levels can indirectly reflect variations in the number of synapses and the gradual process of neuron development. Our research showed that RSV infection was associated with an obvious increase in the SYN expression levels in the adrenal medulla, which decreased with the administration of anti-NGF antibody. These results showed that RSV infection might promote an increase in the number and maturity of the synapses of adrenal medulla cells, but intervention with anti-NGF antibodies promotes the differentiation to neurons. Therefore, we assumed that NGF may be an important inducible factor for this differentiation. However, further experiments need to be undertaken to elucidate the underlying signal transduction mechanisms in details.

From the findings of this study, we concluded that RSV infection results in the overexpression of NGF, which in turn may induce the neuronal differentiation of adrenal medullary cells and thereby reduce their endocrinal function. This leads to a decrease in adrenaline levels in the blood circulation, making it difficult to maintain airway patency and thereby contributing to the progression of asthma. We anticipate that our findings will provide considerable insight into the pathogenesis of asthma and provide a theoretical foundation for elucidating the involvement of neuroendocrine mechanisms.

\section{ACKNOWLEDGMENTS}

Research supported by the National Natural Science Foundation of China (\#30960143). 


\section{REFERENCES}

Aloe L and Levi-Montalcini R (1979). Nerve growth factor-induced transformation of immature chromaffin cells in vivo into sympathetic neurons: effect of antiserum to nerve growth factor. Proc. Natl. Acad. Sci. U. S. A. 76: 1246-1250.

Auais A, Adkins B, Napchan G and Piedimonte G (2003). Immunomodulatory effects of sensory nerves during respiratory syncytial virus infection in rats. Am. J. Physiol. Lung Cell Mol. Physiol. 285: L105-L113.

Bonini S, Lambiase A, Lapucci G, Properzi F, et al. (2002). Nerve growth factor and asthma. Allergy 57 (Suppl 72): 13-15.

Braun A, Lommatzsch M, Lewin GR, Virchow JC, et al. (1999). Neurotrophins: a link between airway inflammation and airway smooth muscle contractility in asthma? Int. Arch. Allergy Immunol. 118: 163-165.

Dong CC, Yin XJ, Ma JY, Millecchia L, et al. (2005). Effect of diesel exhaust particles on allergic reactions and airway responsiveness in ovalbumin-sensitized brown Norway rats. Toxicol. Sci. 88: 202-212.

Feng JT and Hu CP (2005). Dysfunction of releasing adrenaline in asthma by nerve growth factor. Med. Hypotheses 65 : 1043-1046.

Feng JT, Li XZ, Hu CP, Wang J, et al. (2010). Neural plasticity occurs in the adrenal medulla of asthmatic rats. Chin. Med. J. 123: 1333-1337.

Freund-Michel V and Frossard N (2008). The nerve growth factor and its receptors in airway inflammatory diseases. Pharmacol. Ther. 117: 52-76.

Greene LA and Tischler AS (1976). Establishment of a noradrenergic clonal line of rat adrenal pheochromocytoma cells which respond to nerve growth factor. Proc. Natl. Acad. Sci. U. S. A. 73: 2424-2428.

Hahn C, Islamian AP, Renz H and Nockher WA (2006). Airway epithelial cells produce neurotrophins and promote the survival of eosinophils during allergic airway inflammation. J. Allergy Clin. Immunol. 117: 787-794.

$\mathrm{Hu}$ C, Wedde-Beer K, Auais A, Rodriguez MM, et al. (2002). Nerve growth factor and nerve growth factor receptors in respiratory syncytial virus-infected lungs. Am. J. Physiol. Lung Cell Mol. Physiol. 283: L494-L502.

Huang EJ and Reichardt LF (2001). Neurotrophins: roles in neuronal development and function. Annu. Rev. Neurosci. 24: 677-736.

Jun W, Cheng-ping H and Wei-jun L (2007). Study on NGF expression and phenotype transformation of AMCC in asthmatic rats. Chin. J. Pract. Int. Med.

Kasprzak A, Zabel M and Biczysko W (2007). Selected markers (chromogranin A, neuron-specific enolase, synaptophysin, protein gene product 9.5) in diagnosis and prognosis of neuroendocrine pulmonary tumours. Pol. J. Pathol. 58: 23-33.

Lillien LE and Claude P (1985). Nerve growth factor is a mitogen for cultured chromaffin cells. Nature 317: 632-634.

Mohapatra SS and Boyapalle S (2008). Epidemiologic, experimental, and clinical links between respiratory syncytial virus infection and asthma. Clin. Microbiol. Rev. 21: 495-504.

Psarras S, Papadopoulos NG and Johnston SL (2004). Pathogenesis of respiratory syncytial virus bronchiolitis-related wheezing. Paediatr. Respir. Rev. 5 (Suppl A): S179-S184.

Shen XY, Pan PH, Wu ES and Hu CP (2006). Effects of respiratory syncytial virus infection on the airway neuronal plasticity and its relationship to the bronchial hyperresponsiveness in rats. Chin. Med. J. 119: 156-159.

Shojo H and Kibayashi K (2006). Changes in localization of synaptophysin following fluid percussion injury in the rat brain. Brain Res. 1078: 198-211.

Stensballe LG, Simonsen JB, Thomsen SF, Larsen AM, et al. (2009). The causal direction in the association between respiratory syncytial virus hospitalization and asthma. J. Allergy Clin. Immunol. 123: 131-137.

Tortorolo L, Langer A, Polidori G, Vento G, et al. (2005). Neurotrophin overexpression in lower airways of infants with respiratory syncytial virus infection. Am. J. Respir. Crit. Care Med. 172: 233-237.

Unsicker K, Krisch B, Otten U and Thoenen H (1978). Nerve growth factor-induced fiber outgrowth from isolated rat adrenal chromaffin cells: impairment by glucocorticoids. Proc. Natl. Acad. Sci. U. S. A. 75: 3498-3502.

Unsicker K, Huber K, Schutz G and Kalcheim C (2005). The chromaffin cell and its development. Neurochem. Res. 30: 921-925.

Wang J, Hu C and Feng J (2006). Dysfunction of releasing adrenaline in asthmatic adrenaline medullary chromaffin cells due to functional redundancy primed by nerve growth factor. Zhonghua Jie He Hu Xi Za Zhi 29: 812-815.

Wedde-Beer K, Hu C, Rodriguez MM and Piedimonte G (2002). Leukotrienes mediate neurogenic inflammation in lungs of young rats infected with respiratory syncytial virus. Am. J. Physiol. Lung Cel. Mol. Physiol. 282: L1143-L1150.

Welliver RC (2003). Respiratory syncytial virus and other respiratory viruses. Pediatr. Infect. Dis. J. 22: S6-10.

Wiesmann C, Ultsch MH, Bass SH and de Vos AM (1999). Crystal structure of nerve growth factor in complex with the ligand-binding domain of the TrkA receptor. Nature 401: 184-188.

Witzenrath M, Ahrens B, Kube SM, Braun A, et al. (2006). Detection of allergen-induced airway hyperresponsiveness in isolated mouse lungs. Am. J. Physiol. Lung Cell Mol. Physiol. 291: L466-L472.

Ye H, Kuruvilla R, Zweifel LS and Ginty DD (2003). Evidence in support of signaling endosome-based retrograde survival of sympathetic neurons. Neuron 39: 57-68. 